\title{
Faculty Promotion and Attrition: The Importance of Coauthor Network Reach at an Academic Medical Center
}

\author{
Erica T. Warner, Sc.D., M.P.H. ${ }^{7,2}$, René Carapinha, Ph.D., M.A. (SW) ${ }^{7,3}$, Griffin M. Weber, M.D., Ph.D. ${ }^{4,5}$, \\ Emorcia V. Hill, Ph.D. ${ }^{7}$, and Joan Y. Reede, M.D., M.P.H., M.S., M.B.A. ${ }^{7}$
}

'Office for Diversity Inclusion and Community Partnership, Harvard Medical School, Boston, MA, USA; ${ }^{2}$ Department of Epidemiology, Harvard School of Public Health, Boston, MA, USA; ${ }^{3}$ Department of Global Health and Social Medicine, Harvard School of Medicine, Boston, MA, USA; ${ }^{4}$ Center for Biomedical Informatics, Harvard Medical School, Boston, MA, USA; ${ }^{5}$ Department of Medicine, Beth Israel Deaconess Medical Center, Boston, MA, USA.

BACKGROUND: Business literature has demonstrated the importance of networking and connections in career advancement. This is a little-studied area in academic medicine.

OBJECTIVE: To examine predictors of intra-organizational connections, as measured by network reach (the number of first- and second-degree coauthors), and their association with probability of promotion and attrition.

DESIGN: Prospective cohort study between 2008 and 2012.

SETTING: Academic medical center.

PARTICIPANTS: A total of 5787 Harvard Medical School (HMS) faculty with a rank of assistant professor or fulltime instructor as of January 1, 2008.

MAIN MEASURES: Using negative binomial models, multivariable-adjusted predictors of continuous network reach were assessed according to rank. Poisson regression was used to compute relative risk (RR) and $95 \%$ confidence intervals (CI) for the association between network reach (in four categories) and two outcomes: promotion or attrition. Models were adjusted for demographic, professional and productivity metrics.

KEY RESULTS: Network reach was positively associated with number of first-, last- and middle-author publications and $h$-index. Among assistant professors, men and whites had greater network reach than women and underrepresented minorities $(p<0.001)$. Compared to those in the lowest category of network reach in 2008, instructors in the highest category were three times as likely to have been promoted to assistant professor by 2012 (RR: 3.16, 95 \% CI: 2.60, 3.86; p-trend <0.001) after adjustment for covariates. Network reach was positively associated with promotion from assistant to associate professor (RR: 1.82, 95 \% CI: 1.32, 2.50; p-trend <0.001). Those in the highest category of network reach in 2008 were $17 \%$ less likely to have left HMS by 2012 (RR: 0.83, $95 \% \mathrm{CI}$ $0.70,0.98)$ compared to those in the lowest category.

CONCLUSIONS: These results demonstrate that coauthor network metrics can provide useful information for understanding faculty advancement and retention in academic medicine. They can and should be investigated at other institutions.

Received January 23, 2015

Revised May 20, 2015

Accepted June 24, 2015

Published online July 15, 2015
KEY WORDS: faculty development; careers; promotion; retention.

$\mathrm{J}$ Gen Intern Med 31(1):60-7

DOI: $10.1007 / \mathrm{s} 11606-015-3463-7$

(c) Society of General Internal Medicine 2015

\section{INTRODUCTION}

Several studies have shown that minorities and women are less likely to be promoted and more likely to leave academic medical institutions. ${ }^{1-4}$ Faculty members who leave their institutions report feeling disconnected from the organization, that they lack an academic community, and that their careers are not progressing. ${ }^{5}$ Isolation and exclusion are particularly problematic with respect to productivity and advancement in an academic medical research environment, where collaborative science has become an increasingly important component of the landscape. ${ }^{6,7}$ A network of productive colleagues is among the strongest predictors of research publications, productivity, retention and advancement of academic faculty and of career satisfaction among medical school faculty. ${ }^{8-12} \mathrm{~A}$ survey of academic physician educators indicated that their association with people including mentors and peers was an essential element for career fulfillment. ${ }^{9}$ At the organizational level, connections are seen within organizational units that provide the context in which faculty work and train (e.g., labs, centers, divisions, departments). Yet many underrepresented minorities (URMs) and women are marginalized within organizations, including being under the radar, underutilized and hidden talent. Depending on the environment, women are largely viewed individually, while men are viewed in terms of their network and connections. ${ }^{13}$ Creating an organizational climate that fosters networking ${ }^{14}$ is a potential strategy for social integration and inclusion of faculty, particularly URMs and women, in academic medicine.

Numerous studies have examined the importance of networking and connections in business and entrepreneurship as a way of identifying new opportunities and obtaining capital, ${ }^{15-17}$ but this has not been investigated among faculty in academic medicine. ${ }^{18}$ Given the emphasis in academic medicine on scholarship and publication, co-authorship may be among the most critical connections in faculty careers. The 
structure of coauthor networks has a significant impact on career outcomes, including scientific productivity. ${ }^{19} \mathrm{Co}-$ authorship of a published manuscript is evidence of a connection between two or more authors, and collectively, these relationships form a coauthor network. ${ }^{20}$ Coauthor networks within an institution can represent relationships and connections with people, as well as the potential for flow of information, reputation, and plans for future collaboration. ${ }^{21}$ Social capital theory holds that relationship ties within an individual's social network provide access to assets, advice, opportunities and information. ${ }^{22}$ These connections may be particularly important for junior faculty as they build their scientific careers. ${ }^{23}$ Supporting this theory, empirical studies have found that highly productive researchers are those with the highest numbers of research collaborators. ${ }^{24}$ Cross and colleagues (2004), however, found that colleague network size may function independently from scientific output such as published manuscripts and grants awarded..$^{25}$ Coauthor networks within an organization may be influenced by factors such as the number of coauthors per publication, faculty publishing repeatedly with the same coauthors or widely with a larger set of coauthors, and the proportion of coauthors within versus outside the organization.

Using data on faculty at Harvard Medical School as of 2008, we aimed to identify predictors of intra-organizational connections as measured by network reach (the number of first- and second-degree coauthors), and to determine the association between network reach and two outcomes, promotion and attrition.

\section{METHODS}

\section{Study Population}

The study population included HMS faculty with an appointment as either full-time instructor or as full-time or part-time assistant professor as of January 1, $2008(N=5787)$.

\section{Data Sources}

Data are from the Harvard Pathways data repository, which aggregates information on HMS faculty from multiple existing sources-HMS administrative systems provide demographic data and professional characteristics, and a publicly available online directory and social networking tool for Harvard faculty, Harvard Catalyst Profiles ("Profiles") captures facultyauthored publication. ${ }^{26}$ Race/ethnicity is collected by the affiliated hospitals via affirmative action reports submitted with new-hire paperwork. Data collection, usage and security is governed by an institutional data use agreement and overseen by the HMS Committee on Human Subjects (M19492-101).

\section{Profile Publication Data}

Details of the Profiles publication data have been described elsewhere. ${ }^{27}$ In brief, automatic processes regularly import articles from MEDLINE using a name disambiguation algorithm based on the technique described by Torvik and Smalheiser. ${ }^{28}$ In addition to imported articles from MEDLINE, several one-time bulk uploads of publication data from faculty promotion databases and commercial publication sources have been added to the database; faculty can manually add or remove publications. Only publications in Profiles that could be associated with PubMed IDs were used in this study.

\section{Intra-organizational Network "Reach"}

We constructed faculty intra-organizational coauthor networks as of 2008 using Profiles data, with faculty as the vertices (nodes) and their coauthor relationships as the edges (connections). On July 1, 2008, Profiles contained approximately 21,000 faculty and 200,000 connections. Connections to people outside the Profiles population, such as research staff or students at Harvard, and researchers at other institutions are not included in network metrics. The network graph is undirected and unweighted - the connection or relationship between two people who coauthored one publication is treated the same as two people who coauthored 50 publications.

An individual faculty member's intra-organizational coauthor network "reach" is defined as the distinct number of other faculty within two co-authorship "hops" (i.e., the sum of the number of distinct degree 1 and degree 2 coauthors). This captures both a person's coauthors and the coauthors of coauthors. It is the number of faculty an individual faculty member can easily "reach" because they have either directly collaborated with them on a publication in the past or have a colleague in common.

\section{Publication Metrics}

For each faculty member, we calculated the number of publications according to authorship order (first, middle or last), $h$-index, total number of citations across publications, average number of citations per publication and most citations of a single publication (top citation count) in 2008 .

\section{Promotion}

We defined promotion as progression from instructor to assistant professor or from assistant to associate professor. We determined whether faculty had been promoted by December 31, 2012.

\section{Attrition}

We calculated attrition by comparing the roster of HMS faculty with a rank of full-time instructor or assistant professor as of 1 January 2008 with those who remained faculty as of December 31, 2012. Anyone present in 2008 who did not appear in 2012 was considered no longer employed by HMS. 


\section{Demographic and Professional Characteristics}

We categorized race as URM (African-American, Hispanic or American Indian), Asian or Pacific Islander (API) or white. We categorized current rank as instructor (full-time) or assistant professor (full- and part-time). Terminal degree was defined as the highest educational degree attained, with degrees classified as follows: medical (MD, MBBS, DO, etc.), doctoral (PhD, ScD, PsyD, PharmD, EdD), medical/doctoral (any combination of listed MD or PhD degrees) or other (MBA, JD, etc.). A historical job title of HMS "research fellow" or "clinical fellow" defined individuals who participated in HMS fellowship training. We defined work status as full-time or part-time. Discipline was categorized as anesthesia, medicine, neurology, pediatrics, psychiatry, radiology, surgery or other.

\section{Data Analysis}

We stratified faculty by discipline and used negative binomial models to understand the influence of our hypothesized predictors on network reach (as a continuous variable). Estimates are presented for instructors and assistant professors. Hypothesized predictors included demographic and professional characteristics and publication metrics. Due to a large number of faculty with zero coauthors, we used Vuong tests to assess whether zero-inflated models were necessary $(p>0.05)$. Generalized estimating equations generated robust standard errors. Adjustments were made for work status, number of first-, middle- and last-author publications, top citation count, $h$-index, terminal degree, time in rank and history of Harvard fellowship. The variance inflation factor was below 5 for all covariates. Interaction between intra-organizational coauthor network reach, race and gender was evaluated by comparing models with and without cross-product interaction terms and tested using likelihood ratio tests. We ran sensitivity analyses including evaluation of first- and second-degree network size as separate outcomes, and restricting our sample to faculty appointed within a single year (July 1, 2007 to June 30, 2008).

Poisson regression was used to generate relative risk (RR) values and $95 \%$ confidence intervals $(\mathrm{CI})$ for the association between network reach categories in 2008

Table 1 Demographic, Professional and Productivity Characteristics According to Category of Network Reach and Rank in 2008, Instructors at Harvard Medical School $(N=3669)$

\begin{tabular}{|c|c|c|c|c|c|}
\hline & $\begin{array}{l}\text { Total } \\
N=3669\end{array}$ & $\begin{array}{l}\text { Category } 1 \\
N=1630\end{array}$ & $\begin{array}{l}\text { Category } 2 \\
N=683\end{array}$ & $\begin{array}{l}\text { Category } 3 \\
N=675\end{array}$ & $\begin{array}{l}\text { Category } 4 \\
N=681\end{array}$ \\
\hline Category range & & 0 & $1-63$ & $64-187$ & 188-2036 \\
\hline \multicolumn{6}{|l|}{ Median (IQR) } \\
\hline Network reach & $15(132.0)$ & $0(0.0)$ & $27(30)$ & $114(56.0)$ & $306(185.0)$ \\
\hline H-index & $1(2.0)$ & $0(0.0)$ & $1(2.0)$ & $2(2.0)$ & $3(3.0)$ \\
\hline Publications & $2(9.0)$ & $0(0.0)$ & $4(6.0)$ & $6(9.0)$ & $14(14.0)$ \\
\hline Coauthors & $1(6.0)$ & $0(0.0)$ & $2(2.0)$ & $5(3.0)$ & $13(10.0)$ \\
\hline 1 st auth. pubs & $1(3.0)$ & $0(0.0)$ & $2(3.0)$ & $2(4.0)$ & $4(5.0)$ \\
\hline \multicolumn{6}{|l|}{$\mathrm{N}(\%)$} \\
\hline \multicolumn{6}{|l|}{ Race } \\
\hline $\mathrm{API}^{*}$ & 773 (21.7) & $392(24.6)$ & 124 (18.6) & $114(17.6)$ & $143(21.9)$ \\
\hline $\mathrm{URM}^{\dagger}$ & $258(7.3)$ & $138(8.7)$ & $40(6.0)$ & $43(6.6)$ & $37(5.7)$ \\
\hline White & $2527(71.0)$ & $1062(66.7)$ & $502(75.4)$ & $491(75.8)$ & $472(72.4)$ \\
\hline \multicolumn{6}{|l|}{ Gender } \\
\hline Female & $1799(49.1)$ & 903 (55.4) & $335(49.1)$ & $299(44.3)$ & $262(38.5)$ \\
\hline \multicolumn{6}{|l|}{ Age group (years) } \\
\hline$<40$ & $903(24.6)$ & $412(25.3)$ & $197(28.8)$ & $145(21.5)$ & 149 (21.9) \\
\hline $40-49$ & $1780(48.5)$ & $690(42.3)$ & $329(48.2)$ & $378(56.0)$ & $383(56.2)$ \\
\hline $50-59$ & $704(19.2)$ & $348(21.4)$ & $122(17.9)$ & $112(16.6)$ & $122(17.9)$ \\
\hline$\geq 60$ & $282(7.7)$ & $180(11.0)$ & $35(5.1)$ & $40(5.9)$ & $27(4.0)$ \\
\hline \multicolumn{6}{|l|}{ Terminal degree } \\
\hline $\mathrm{MD} / \mathrm{PhD}$ & $246(6.7)$ & $72(4.4)$ & $49(7.2)$ & $42(6.2)$ & $83(12.2)$ \\
\hline MD only & $2327(63.4)$ & $1178(72.3)$ & $417(61.1)$ & $383(56.7)$ & $349(51.3)$ \\
\hline $\mathrm{PhD}$ only & $954(26.0)$ & 325 (19.9) & $182(26.7)$ & 229 (33.9) & $218(32.0)$ \\
\hline Other degree & $142(3.9)$ & $55(3.4)$ & $35(5.1)$ & $21(3.1)$ & $31(4.6)$ \\
\hline \multicolumn{6}{|l|}{ HMS fellowship } \\
\hline Yes & 2474 (67.4) & 899 (55.2) & $495(72.5)$ & $527(78.1)$ & $553(81.2)$ \\
\hline \multicolumn{6}{|l|}{ Discipline } \\
\hline Anesthesia & $152(4.1)$ & $73(4.5)$ & $40(5.9)$ & $25(3.7)$ & $14(2.1)$ \\
\hline Medicine & $1375(37.5)$ & $664(40.7)$ & $194(28.4)$ & 254 (37.6) & $263(38.6)$ \\
\hline Neurology & $182(5.0)$ & $45(2.8)$ & $45(6.7)$ & $45(6.7)$ & $47(6.9)$ \\
\hline Pediatrics & $393(10.7)$ & $167(10.3)$ & 77 (11.3) & 78 (11.6) & $71(10.4)$ \\
\hline Psychiatry & $495(13.5)$ & $292(17.9)$ & 95 (13.9) & $76(11.3)$ & $32(4.7)$ \\
\hline Radiology & $219(6.0)$ & $76(4.7)$ & $24(3.5)$ & $39(5.8)$ & $80(11.8)$ \\
\hline Surgery & $254(6.9)$ & $80(4.9)$ & $49(7.2)$ & $46(6.8)$ & 79 (11.6) \\
\hline Other & $599(16.3)$ & $233(14.3)$ & $159(23.2)$ & $112(16.6)$ & $95(14.0)$ \\
\hline
\end{tabular}

*API: Asian or Pacific Islander; ${ }^{\dagger}$ URM: underrepresented minority (includes African-American, Hispanic and Native American). IQR interquartile range 
(using rank-specific cutpoints) and probability of promotion by 2012, as well as probability of leaving HMS by 2012. We divided network reach into four categories. Separate category cutpoints were estimated for instructors and assistant professors based on the distribution of network reach among faculty at each rank. Among instructors, we created a category for all faculty with network reach of zero. Instructors with network reach values greater than zero were then divided into tertiles, for a total of four categories. The assistant professors were categorized into quartiles. Models were stratified by discipline, and robust standard errors were generated. Since criteria for promotion and distribution of network reach differed by rank, separate models for each starting rank (instructor or assistant professor) were run. Estimates adjusted for age and time in rank only and multivariable models with additional adjustment for the full list of covariates included in our model for network reach are presented. Work status was not included in the promotion model for instructors, as part-time instructors were excluded; however, work status was included in the promotion model for assistant professor. $\mathrm{P}$ values are two-sided and use a significance level of
0.05 . Analyses were performed using SAS version 9.3 statistical software (SAS Institute Inc., Cary, NC, USA).

\section{RESULTS}

Tables 1 and 2 show the characteristics of faculty stratified by rank, in total and according to coauthor network reach category. Instructors had a median network reach of 14.0 and median of 2.0 publications (Table 1), while assistant professors had a median network reach of 132.0 and 14.0 publications (Table 2). Network reach was lower for URMs and women compared to whites and men, as both groups were overrepresented in the lowest categories of network reach among instructors and assistant professors. Faculty aged 60 years and older represented $23.4 \%$ of the total assistant professor population but only $8.5 \%$ of faculty in the highest category of network reach. In multivariable adjusted models, there was no gender difference in network reach (Table 3). URM faculty had lower network reach than whites among instructors (RR: $0.75,95 \%$ CI: 0.59, 0.96) and assistant professors (RR: $0.79,95 \%$ CI: $0.62,1.00$ ). API faculty had

Table 2 Demographic, Professional and Productivity Characteristics According to Category of Network Reach and Rank in 2008, Assistant Professors at Harvard Medical School $(N=\mathbf{2 1 1 8})$

\begin{tabular}{|c|c|c|c|c|c|}
\hline & $\begin{array}{l}\text { Total } \\
N=\mathbf{2 1 1 8}\end{array}$ & $\begin{array}{l}\text { Category } 1 \\
N=525\end{array}$ & $\begin{array}{l}\text { Category } 2 \\
N=533\end{array}$ & $\begin{array}{l}\text { Category } 3 \\
N=531\end{array}$ & $\begin{array}{l}\text { Category } 4 \\
N=529\end{array}$ \\
\hline Category range & & $0-5$ & $6-131$ & $132-345$ & $346-2451$ \\
\hline \multicolumn{6}{|l|}{ Median (IQR) } \\
\hline Network reach & $132(339.0)$ & $0(0.0)$ & 56. (68.0) & $231(104.0)$ & $540(281.0)$ \\
\hline H-index & $2(4.0)$ & $0(0.0)$ & $2(2.0)$ & $3(4.0)$ & $5(5.0)$ \\
\hline Publications & $14(26.0)$ & $0(1.0)$ & $9(14.0)$ & $19(18.0)$ & $36(30.0)$ \\
\hline Coauthors & $6(15.0)$ & $0(0.0)$ & $3(4.0)$ & $10(7.0)$ & $25(17.0)$ \\
\hline 1st auth. pubs & $4(9.0)$ & $0(3.0)$ & $3(7.0)$ & $6(7.0)$ & $9(9.0)$ \\
\hline \multicolumn{6}{|l|}{$N(\%)$} \\
\hline \multicolumn{6}{|l|}{ Race } \\
\hline $\mathrm{API}^{*}$ & $359(17.2)$ & $116(22.3)$ & $69(13.1)$ & $79(15.2)$ & 95 (18.2) \\
\hline $\mathrm{URM}^{\dagger}$ & $102(4.9)$ & $31(6.0)$ & $32(6.1)$ & $22(4.2)$ & $17(3.3)$ \\
\hline White & $1625(77.9)$ & $373(71.7)$ & $425(80.8)$ & $418(80.5)$ & $409(78.5)$ \\
\hline \multicolumn{6}{|l|}{ Gender } \\
\hline Female & $755(35.7)$ & $194(37.0)$ & $197(37.0)$ & $193(36.4)$ & $171(32.3)$ \\
\hline \multicolumn{6}{|l|}{ Age group (years) } \\
\hline$<40$ & $73(3.5)$ & $15(2.9)$ & $15(2.8)$ & $23(4.3)$ & $20(3.8)$ \\
\hline $40-49$ & $866(40.9)$ & $143(27.2)$ & $177(33.2)$ & $265(49.9)$ & $281(53.1)$ \\
\hline $50-59$ & $684(32.3)$ & $161(30.7)$ & $183(34.3)$ & $157(29.6)$ & $183(34.6)$ \\
\hline$\geq 60$ & $495(23.4)$ & $206(39.2)$ & $158(29.6)$ & $86(16.2)$ & $45(8.5)$ \\
\hline \multicolumn{6}{|l|}{ Terminal degree } \\
\hline $\mathrm{MD} / \mathrm{PhD}$ & $207(9.8)$ & $33(6.3)$ & $39(7.3)$ & $56(10.6)$ & 79 (14.9) \\
\hline MD only & $1324(62.5)$ & $347(66.1)$ & $328(61.5)$ & $326(61.4)$ & $323(61.1)$ \\
\hline $\mathrm{PhD}$ only & $519(24.5)$ & $132(25.1)$ & $144(27.0)$ & $137(25.8)$ & $106(20.0)$ \\
\hline Other degree & $68(3.2)$ & $13(2.5)$ & $22(4.1)$ & $12(2.3)$ & $21(4.0)$ \\
\hline \multicolumn{6}{|l|}{ Work Status } \\
\hline Full-time & $1720(81.2)$ & $345(65.7)$ & $404(75.8)$ & $467(88.0)$ & $504(95.3)$ \\
\hline HMS fellowshin & & & & & \\
\hline Yes & $1442(68.1)$ & $318(60.6)$ & $319(59.9)$ & $384(72.3)$ & $421(79.6)$ \\
\hline \multicolumn{6}{|l|}{ Discipline } \\
\hline Anesthesia & $78(3.7)$ & $22(4.2)$ & $26(4.9)$ & $19(3.9)$ & $11(2.1)$ \\
\hline Medicine & $675(31.9)$ & $155(29.5)$ & $135(25.3)$ & $177(33.3)$ & $208(39.3)$ \\
\hline Neurology & $99(4.7)$ & $26(5.0)$ & $20(3.8)$ & $28(5.3)$ & $25(4.7)$ \\
\hline Pediatrics & $227(10.7)$ & $46(8.8)$ & $63(11.8)$ & $57(10.7)$ & $61(11.5)$ \\
\hline Psychiatry & $300(14.2)$ & $119(22.7)$ & $102(19.1)$ & $57(10.7)$ & $22(4.2)$ \\
\hline Radiology & $135(6.4)$ & $25(4.8)$ & $14(2.6)$ & $47(8.9)$ & $49(9.3)$ \\
\hline Surgery & 147 (6.9) & $23(4.4)$ & $26(4.9)$ & $52(9.8)$ & $46(8.7)$ \\
\hline Other & $457(21.2)$ & $109(20.8)$ & $147(27.6)$ & $94(17.8)$ & $117(20.2)$ \\
\hline
\end{tabular}

* API: Asian or Pacific Islander; ${ }^{\dagger}$ URM: Underrepresented minority (includes African-American, Hispanic and Native American. IQR interquartile range 
lower network reach than whites among instructors (RR: 0.84, $95 \%$ CI: 0.71, 0.98), while there was no difference among assistant professors (RR: 0.96, $95 \%$ CI: 0.82, 1.12). Other important predictors of network reach were age, $h$-index, terminal degree and HMS fellowship.

Approximately one-fifth (21.5\%) of instructors in 2008 had been promoted by 2012 (Table 4). In models adjusted for age and time in rank, greater network reach was associated with higher probability of promotion. Those in the highest category were over three times as likely to have been promoted as those in the lowest category (RR: 3.59, $95 \%$ CI: 3.03, 4.25). In the multivariable adjusted model, those in the highest network reach category were still more than three times as likely to have been promoted (RR: 3.16, $95 \%$ CI: $2.60,3.86$ ). In the multivariable adjusted model, other predictors of promotion to assistant professor included age, time in rank and number of first-author publications (data not shown).

Promotion to associate professor occurred for $22.0 \%$ of assistant professors (Table 4). In models adjusted for age and time in rank, those in the highest category of network reach in 2008 were over three times as likely to have been promoted by 2012 as those in the lowest category (RR: 3.07, $95 \%$ CI: 2.32, 4.06). The association was attenuated, but remained significant, in the multivariable adjusted model (RR: $1.82,95 \% \mathrm{CI}$ : $1.32,2.50)$. In the multivariable adjusted model, other predictors of promotion to associate professor included age, time in rank, number of first-author publications and number of lastauthor publications (data not shown).

Faculty attrition from HMS between 2008 and 2012 was $21.2 \%$ (Table 5). In the age-adjusted model, faculty in the highest reach category were $21 \%$ less likely to have left HMS than those in the lowest category (RR: $0.79,95 \%$ CI: 0.69 , 0.91). After adjustment for demographic, professional and productivity factors, the association was slightly attenuated but remained significant (RR: 0.83, $95 \%$ CI: 0.70, 0.98). In the multivariable adjusted model, other predictors of attrition included age, time in rank, rank, full- or part-time status, terminal degree and race (data not shown).

We found no evidence of statistical interaction between network reach and race or gender $(p>0.05)$. Results were not significantly changed in sensitivity analyses where first- or second-degree network size was the dependent variable or when we restricted our sample to faculty who were appointed within a single year (1 July 2007 to 30 June 2008).

\section{DISCUSSION}

HMS junior faculty with greater intra-organizational coauthor network reach in 2008 were more likely to have been promoted and less likely to have left the institution by 2012 . The associations we observed were independent of productivity metrics such as number of first-, middle- and last-author publications and $h$-index. These results suggest that while productivity metrics play a role in promotion, connections matter. Intra-organizational network reach represents relationships that are solidified by the production of publications.

Our study demonstrates that data from administrative databases can be combined with faculty coauthor network data to examine factors related to faculty promotion and retention. Within one academic medical center and across multiple disciplines, network reach was positively related to promotion and retention. This suggests that internal connections should be considered in designing, implementing and evaluating faculty development programs, and more generally in programs that enhance diversity inclusion and foster supportive environments in academic medicine. While this study was conducted at a single institution, it could be replicated at institutions across the nation. The coauthor network data used in this analysis come from Profiles Research Networking Software that is available for free under an open source license, and has been implemented at over 40 institutions, including Boston University and the University of California at San Francisco. ${ }^{29,30}$ Our findings can and should be examined in other settings.

We identified several significant demographic and bibliometric predictors of intra-organizational coauthor network reach. Among assistant professors, when we adjusted for productivity metrics such as number of publications, no gender differences in network reach were found, although networks were smaller for URM faculty than white faculty. URM and API instructors also had lower

Table 3 Predictors of Network Reach According to Rank in 2008, Harvard Medical School

\begin{tabular}{|c|c|c|}
\hline \multirow[t]{2}{*}{$\overline{\text { Characteristic }}$} & \multicolumn{2}{|c|}{ Multivariable adjusted RR (95\% CI) } \\
\hline & $\begin{array}{l}\text { Instructors } \\
N=3669\end{array}$ & $\begin{array}{l}\text { Assistant Professors } \\
N=\mathbf{2 1 1 8}\end{array}$ \\
\hline \multicolumn{3}{|l|}{ Gender } \\
\hline Male & 1.00 (Ref) & 1.00 (Ref) \\
\hline Female & $0.91(0.81,1.03)$ & $1.07(0.96,1.19)$ \\
\hline \multicolumn{3}{|l|}{ Race } \\
\hline White & 1.00 (Ref) & 1.00 (Ref) \\
\hline URM & $0.75(0.59,0.96)$ & $0.79(0.62,1.00)$ \\
\hline API & $0.84(0.71,0.98)$ & $0.96(0.82,1.12)$ \\
\hline \multicolumn{3}{|l|}{ Age group (years) } \\
\hline$<40$ & 1.00 (Ref) & 1.00 (Ref) \\
\hline $40-49$ & $1.17(1.01,1.36)$ & $1.11(0.85,1.45)$ \\
\hline $50-59$ & $1.00(0.80,1.26)$ & $1.01(0.76,1.33)$ \\
\hline$\geq 60$ & $0.65(0.44,0.96)$ & $0.65(0.47,0.89)$ \\
\hline Time in rank (yrs) & $1.00(0.98,1.01)$ & $1.00(0.99,1.01)$ \\
\hline H-index & $1.32(1.28,1.37)$ & $1.14(1.12,1.16)$ \\
\hline Number of publications & $1.08(1.08,1.10)$ & $1.03(1.03,1.05)$ \\
\hline \multicolumn{3}{|l|}{ Terminal degree } \\
\hline $\mathrm{MD} / \mathrm{PhD}$ & 1.00 (Ref) & 1.00 (Ref) \\
\hline MD only & $1.08(0.86,1.37)$ & $1.02(0.85,1.22)$ \\
\hline $\mathrm{PhD}$ only & $0.94(0.74,1.19)$ & $0.68(0.56,0.84)$ \\
\hline \multicolumn{3}{|l|}{ Work Status } \\
\hline Part-time & & 1.00 \\
\hline & & $2.02(1.72,2.36)$ \\
\hline \multicolumn{3}{|l|}{ HMS Fellowship } \\
\hline No & 1.00 (Ref) & 1.00 (Ref) \\
\hline Yes & $1.87(1.61,2.16)$ & $1.21(1.07,1.37)$ \\
\hline
\end{tabular}

* Adjusted for age and time in rank as of 1 January 2008, race, gender, terminal degree, work status (except instructors), HMS fellowship and highest citation count; $R R$ relative risk 
Table 4 Association between Network Reach in 2008 and Promotion by 2012: Instructor to Assistant Professor and Assistant Professor to Associate Professor

\begin{tabular}{|c|c|c|c|c|c|c|c|c|c|}
\hline \multicolumn{5}{|c|}{ Instructor to Assistant Professor } & \multicolumn{5}{|c|}{ Assistant Professor to Associate Professor } \\
\hline Characteristic & Number & $\begin{array}{l}\text { Number } \\
\text { promoted }\end{array}$ & $\begin{array}{l}\text { Age- } \\
\text { adjusted* } \\
\operatorname{RR}(95 \% \text { CI) }\end{array}$ & $\begin{array}{l}\text { MV- } \\
\text { adjusted }{ }^{\dagger} \\
\operatorname{RR}(95 \% \text { CI) }\end{array}$ & Characteristic & Number & $\begin{array}{l}\text { Number } \\
\text { Promoted }\end{array}$ & $\begin{array}{l}\text { Age- } \\
\text { adjusted } \\
\text { RR } \\
(\mathbf{9 5} \% \mathrm{CI})\end{array}$ & $\begin{array}{l}\text { MV- } \\
\text { adjusted } \\
\text { RR } \\
\text { (95\% CI) }\end{array}$ \\
\hline Network reach & & & \multirow{6}{*}{$\begin{array}{l}1.00 \text { (Ref) } \\
1.85 \\
(1.51,2.27) \\
2.86 \\
(140,3.42) \\
3.59 \\
(3.03,4.25) \\
<0.0001\end{array}$} & \multirow{6}{*}{$\begin{array}{l}1.00 \text { (Ref) } \\
1.74 \\
(1.41,2.14) \\
2.57 \\
(2.12,3.12) \\
3.16 \\
(2.60,3.86) \\
<0.0001\end{array}$} & Network Reach & & & \multirow{6}{*}{$\begin{array}{l}1.00 \text { (Ref) } \\
1.28 \\
(0.93,1.78) \\
1.68 \\
(1.24,2.27) \\
3.07 \\
(2.32,4.06) \\
<0.0001\end{array}$} & \multirow{6}{*}{$\begin{array}{l}1.00 \text { (Ref) } \\
1.00 \\
(0.72,1.38) \\
1.19 \\
(0.87,1.64) \\
1.82 \\
(1.32,2.50) \\
<0.0001\end{array}$} \\
\hline & 1630 & 173 & & & & 525 & 51 & & \\
\hline $1-63$ & 683 & 138 & & & $6-131$ & 533 & 74 & & \\
\hline $64-187$ & 675 & 213 & & & $132-345$ & 531 & 115 & & \\
\hline 188-2036 & 681 & 266 & & & $346-2451$ & 529 & 225 & & \\
\hline p-trend & & & & & p-trend & & & & \\
\hline
\end{tabular}

*Adjusted for age and time in rank as of 1 January 2008; ${ }^{*}$ adjusted for age and time in rank plus race, gender, terminal degree, prior HMS fellowship, top citation count, h-index, number of publications, number of first-author publications; ${ }^{*}$ adjusted for age and time in rank plus race, gender, terminal degree, prior Harvard fellowship, full-time work status, top citation count, h-index, number of first-author publications, number of middle-author publications and number of last-author publications. RR relative risk, MV multivariable

network reach. Smaller intra-organizational coauthor networks may reflect a tendency for URM faculty to collaborate with faculty outside their institution. Some have suggested that URM faculty may experience difficulties establishing and building relationships within their institution, and therefore look elsewhere for collaborators. ${ }^{31}$ At least one study found that URM and female faculty in the sciences had larger self-reported collaborator networks overall compared to white and male faculty; however, they were more productive with external than internal collaborators. ${ }^{23}$ Our current study did not examine the relative proportion of faculty networks that were within versus outside HMS. It will be important in the future to understand the relationships between intra-organizational network reach and external network reach and whether these relationships vary by race/ethnicity and/or gender. It is also important to understand how research topic ${ }^{32}$ and demographic composition of networks and homophily may contribute to racial and gender differences in network reach.

Network reach includes the cumulative publication history of each faculty member through 2008. Publication patterns have changed over time, and this has implications for our findings. For example, between 1956 and 1980, 69.5\% of papers had a single author, yet only $15.5 \%$ had a single author between 2001 and $2008 .^{32}$ This may contribute to the inverse association between network reach and age found in this study. Older faculty and those who have been in an organization for a longer period may have more colleagues that are no longer a part of the organization, having moved to another institution or retired. This would result in lower intra-organizational network reach.

How might network reach influence promotion and attrition? Larger networks can provide more new and diversified resources than smaller networks. ${ }^{33}$ Literature suggests that the structure of coauthor networks has a significant impact on career outcomes, including scientific productivity. ${ }^{19}$ Larger networks may be markers of visibility, providing opportunities for increased awareness by other faculty and administrators, and thereby serving as vehicles for conveying one's reputation to others to whom one is not directly connected. For junior faculty, networks may be influenced by patterns of inclusion, supportive environments and mentoring. Social networks may provide benefits to individuals through access to embedded resources. ${ }^{34,35}$ For example, effective mentors who are well connected may connect mentees with other well-connected members of their network. ${ }^{36}$

Table 5 Association between Network Reach in 2008 and Attrition by 2012

\begin{tabular}{lllll}
\hline \hline Characteristic & $\begin{array}{l}\text { Number } \\
\text { in category }\end{array}$ & $\begin{array}{l}\text { Number who } \\
\text { left HMS }\end{array}$ & $\begin{array}{l}\text { Age-adjusted } \\
\text { RR (95 \% CI) }\end{array}$ & $\begin{array}{l}\text { MV-adjusted } \\
\text { RR (95 \% CI) }\end{array}$ \\
\hline Network reach $\dagger$ & & & & \\
0 & 2155 & 491 & 1.00 (Ref) & $1.00($ Ref) \\
$1-63$ & 1266 & 268 & $0.97(0.86,1.11)$ & $0.99(0.86,1.13)$ \\
$64-187$ & 1206 & 245 & $0.88(0.77,1.01)$ & $0.91(078,1.06)$ \\
$188-2036$ & 1210 & 223 & $0.79(0.69,0.91)$ & $0.83(0.70,0.98)$ \\
p-trend & & & $<0.0001$ & \\
\hline
\end{tabular}

${ }^{*}$ Adjusted for age and time in rank as of 1 January 2008; ${ }^{\dagger}$ adjusted for age and time in rank plus race, gender, faculty rank, terminal degree, prior Harvard fellowship, full-time work status, h-index, number of first-author publications, number of middle-author publications and number of last-author publications

Note: *Uses rank-specific cutpoints. Cutpoints presented are for instructors. Cut points for assistant professors were: 0-5, 6-131, 132-345, and 346245. RR relative risk, HMS Harvard Medical School, MV multivariable 
Moving forward, we must understand how faculty coauthor networks map onto individual's perceived networks, including any instrumental (e.g., influence, communication, advice) and expressive (e.g., friendship) functions. ${ }^{37,38}$ Also unknown are the mechanisms by which information and other capital are exchanged, as well as how strength of network ties ${ }^{39}$ versus number of connections may influence promotion or attrition. Authorship order may matter - a stronger or more meaningful relationship may exist when coauthors are first and last authors or first and second authors, than for relationships among middle authors. In this study, network calculations did not weight relationships for author order or the number of times papers were coauthored. However, adjustments were made for number of first/middle/last-author papers.

Study limitations include difficulty disambiguating common names or name changes. Coauthor network reach is a PubMed publication-based metric, and may not fully capture other salient metrics relevant to the advancement of all faculty types, such as clinician educators. Not all types of HMS coauthor relations are captured - only those in MEDLINEindexed journals. This study was conducted at a single institution with a strong research focus, and study results may not be fully generalizable to other institutions, including those with a less intensive research focus. However, the central construct of intra-organizational connections in relation to promotion and attrition can be examined elsewhere.

In conclusion, we found that HMS faculty with greater network reach were more likely to have been promoted and less likely to have left the institution by 2012 . These results highlight the importance of connection and suggest that coauthor relationships contribute to advancement and retention in academic medicine.

Acknowledgments: This work was supported by an NIH Directors Pathfinders Award Grant 1DP4GM096852 from the National Institute of General Medical Sciences and by grant number B07-07 from the Josiah Macy Jr. Foundation. Dr. Warner was supported by National Cancer Institute grants 5T32CA009001-36 and 1K01CA188075-01. The authors would like to thank Amy Sullivan, Kimberly Boucher, Megan Pasquantonio-Pierce, Ken Huling and Steve Wimberg for their contributions to data preparation and organization. The authors would also like to thank the members of the Harvard University Pathways Study Research, Executive, User, and Data Security Advisory Committees for their guidance and thoughtful feedback.

Conflict of Interest: The authors declare that they do not have a conflict of interest.

Corresponding Author: Erica T. Warner, Sc.D., M.P.H.; Department of Epidemiology, Harvard School of Public Health, 181 Longwood Ave., Room 452, Boston, MA 02115, USA (e-mail: ewarner@hsph.harvard.edu).

\section{REFERENCES}

1. Daley S, Wingard DL, Reznik V. Improving the retention of underrepresented minority faculty in academic medicine. J Natl Med Assoc. 2006;98(9): 1435 .

2. Fang D, Moy E, Colburn L, Hurley J. Racial and ethnic disparities in faculty promotion in academic medicine. JAMA. 2000;284(9): 1085-92.
3. Nonnemaker L. Women physicians in academic medicine--new insights from cohort studies. N Engl J Med. 2000;342(6):399-405.

4. Tesch BJ, Wood HM, Helwig AL, Nattinger AB. Promotion of women physicians in academic medicine. JAMA. 1995;273(13):1022-5.

5. Lowenstein SR, Fernandez G, Crane LA. Medical school faculty discontent: Prevalence and predictors of intent to leave academic careers. BMC Med Educ. 2007;7(1):37.

6. 2003 the impact of research collaboration on scientific productivity. Available at: http://gtresearchnews.gatech.edu/newsrelease/Collab.pdf. Accessed 6/22/2015.

7. Hampton SE, Parker JN. Collaboration and productivity in scientific synthesis. BioScience. 2001;61(11):900.

8. Bland CJ, Seaquist E, Pacala JT, Center B, Finstad D. One school's strategy to assess and improve the vitality of its faculty. Acad Med. 2002;77(5):368

9. Simpson DE, Rediske VA, Beecher A, et al. Understanding the careers of physician educators in family medicine. Acad Med. 2001;76(3):259.

10. Morzinski JA, Fisher JC. A nationwide study of the influence of faculty development programs on colleague relationships. Acad Med. 2002;77(5):402.

11. Hitchcock MA, Hekelman FP, Monteiro M, Snyder CW. Acquiring professional academic skills. In: Lowenstein SR, Fernandez G, Crane LA, editors. Medical school faculty discontent: prevalence and predictors of intent to leave academic careers. BMC Med Educ. 2007;7(1):37.

12. Hitchcock MA, Bland CJ, Hekelman FP, Blumenthal MG. Professional networks: The influence of colleagues on the academic success of faculty. Acad Med. 1995;70(12):1108-16.

13. O'Neil DA, Hopkins MM, Sullivan SE. Do women's networks help advance women's careers? differences in perceptions of female workers and top leadership. Career Development International. 2011;16(7):733-54.

14. Schweer M, Assimakopoulos D, Cross R, Thomas RJ. Building a wellnetworked organization. MIT Sloan Manage Rev. 2011;53(2):35-42.

15. Rhodes C, Butler JS. Organizational membership and business success: The importance of networking and moving beyond homophily. Challenge (1077193X). 2010;16(1).

16. Chandwani R, Srinivasan V, Jha M, Nagadevara V. In: Politics of social enterprises: The role of influential people in scaling up. Academy of Management Annual Meeting proceedings; Academy of Management; 2013. p. 11214 .

17. Watson J. Modeling the relationship between networking and firm performance. J Bus Venturing. 2007;22(6):852-74.

18. Jarratt D, Duncan R, Bossomaier T. It's not only what you know: Simulating research networks in the UK university sector. Emergence: Complexity \& Organization. 2014;16(2).

19. Adler PS, Kwon Sw. Social capital: Prospects for a new concept. Acad Manag Rev. 2002;27(1):17.

20. Newman ME. Coauthorship networks and patterns of scientific collaboration. Proc Natl Acad Sci U S A. 2004;101(Suppl 1):5200-5.

21. Mali F, Kronegger L, Doreian P, Ferligoj A. Dynamic scientific coauthorship networks. In: Models of Science Dynamics. Springer; 2012. p. 195-232.

22. Burt RS. Structural holes: The social structure of competition. Harvard University Press; 2009.

23. Pinheiro DL, Melkers JE. In: The need to look elsewhere: The push and pull of underrepresented minority faculty professional networks. 2011 Atlanta Conference on Science and Innovation Policy. IEEE; 2011. p. 1-15.

24. Abbasi A, Altmann J, Hossain L. Identifying the effects of co-authorship networks on the performance of scholars: A correlation and regression analysis of performance measures and social network analysis measures. J Informetr. 2011;5(4):594-607.

25. Cross R, Cummings JN. Tie and network correlates of individual performance in knowledge-intensive work. Acad Manag J. 2004;47(6):928-37.

26. 2013 Harvard Catalyst Profiles website. Available at: http://connects. catalyst.harvard.edu/profiles. Accessed 06/22/2015.

27. Warner ET, Carapinha R, Weber GM, Hill EV, Reede JY. Considering context in academic medicine: Differences in demographic and professional characteristics and in research productivity and advancement metrics across seven clinical departments. Acad Med. 2015.

28. Torvik VI, Smalheiser NR. Author name disambiguation in MEDLINE. ACM Transactions on Knowledge Discovery from Data (TKDD). 2009;3(3): 11.

29. Weber GM, Barnett W, Conlon M, et al. Direct2Experts: A pilot national network to demonstrate interoperability among research-networking platforms. J Am Med Inform Assoc. 2011;18(Suppl 1):i157-60. 
30. Kahlon M, Yuan L, Daigre J, et al. The use and significance of a research networking system. J Med Internet Res. 2014;16(2), e46.

31. Katz JS, Martin BR. What is research collaboration? Res Policy. 1997;26:1.

32. Ding Y. Scientific collaboration and endorsement: Network analysis of coauthorship and citation networks. J Informetr. 2011;5(1):187-203.

33. Coviello NE. The network dynamics of international new ventures. J Int Bus Stud. 2006;37(5):713-31.

34. Leboy PS, Madden JF. Limitations on diversity in basic science departments. DNA Cell Biol. 2012;31(8): 1365.

35. Podolny JM, Baron JN. Resources and relationships: Social networks and mobility in the workplace. Am Sociol Rev. 1997:673-93.
36. DeCastro R, Sambuco D, Ubel PA, Stewart A, Jagsi R. Mentor networks in academic medicine: Moving beyond a dyadic conception of mentoring for junior faculty researchers. Acad Med. 2013;88(4):48896.

37. Ibarra H. Homophily and differential returns: Sex differences in network structure and access in an advertising firm. Adm Sci Q. 1992:422-47.

38. Totterdell P, Holman D, Hukin A. Social networkers: Measuring and examining individual differences in propensity to connect with others. Social Networks. 2008;30(4):283-96.

39. Rost K. The strength of strong ties in the creation of innovation. Research Policy. 2011;40(4):588-604. 